\title{
Effect of TachoSil Patch in Prevention of Postoperative Pancreatic Fistula
}

\author{
Irina Pavlik Marangos • Bård I. Røsok • \\ Airazat M. Kazaryan • Arne R. Rosseland • \\ Bjørn Edwin
}

Received: 28 April 2011 / Accepted: 2 June 2011 /Published online: 14 June 2011

(C) The Author(s) 2011. This article is published with open access at Springerlink.com

\begin{abstract}
Background Postoperative pancreatic fistula (POPF) is a severe complication after pancreatic resections. The aim was to assess if application of TachoSil ${ }^{\circledR}$ patch could reduce incidence of postoperative fistulas after laparoscopic distal pancreatic resections.

Methods This is a retrospective study of prospectively collected data after enucleations and distal pancreatic resections. Patients were divided in two groups: with or without application of TachoSil ${ }^{\circledR}$ patch. Demographic and surgical data were analyzed.

Results One hundred twenty-one patients with distal pancreatic resections without additional resections were identified among 230 patients operated by laparoscopic approach at our institution since 1998. They were divided into two groups. In group $1(n=48)$, TachoSil ${ }^{\circledR}$ patch was not applied while in group $2(n=73)$, the pancreatic stump was covered with $\mathrm{TachoSil}^{\circledR}$. Postoperative fistulas were registered in $8 \%(4 / 48)$ and $12 \%(9 / 73)$ in groups 1 and 2 , respectively. The median duration of postoperative hospital stay in group 1 was 5.5 (2-35) days compared with 5 (2-16) days in group 2 . No significant difference in surgical outcomes was found.

Conclusions The application of the TachoSil ${ }^{\circledR}$ patch did not affect either occurrence of POPF or duration of postoperative hospital stay. Routine use of TachoSil ${ }^{\circledR}$ patch to prevent pancreatic fistulas does not provide clinically significant benefit.
\end{abstract}

I. Pavlik Marangos $(\bowtie) \cdot$ A. M. Kazaryan • B. Edwin

The Interventional Centre, Oslo University Hospital,

Rikshospitalet,

0027 Oslo, Norway

e-mail: irinapavlik25@gmail.com

I. Pavlik Marangos

e-mail: Irina.Pavlik.Marangos@ous-hf.no

I. Pavlik Marangos · A. M. Kazaryan

Institute of Clinical Medicine, Faculty of Medicine,

University of Oslo,

Oslo, Norway

B. I. Røsok · A. R. Rosseland · B. Edwin

Department of Hepatic and Gastrointestinal Surgery,

Oslo University Hospital,

Rikshospitalet,

Oslo, Norway

A. M. Kazaryan

Department of Surgery, Vestre Viken, Drammen Hospital,

Drammen, Norway
Keywords Postoperative complication · Pancreatic fistula TachoSil $\cdot$ Pancreas resection

\section{Introduction}

The laparoscopic approach for distal pancreatic resections has gained increased acceptance for several indications during the past decade and an increasing number of patients is operated by this method both for nonmalignant as well as for malignant diseases. There is increasing documentation that both endocrine tumors, cystic lesions, metastatic lesions, and adenocarcinomas can be safely operated by the laparoscopic approach ${ }^{1-3}$ and the implementation of minimally invasive techniques has led to reduced morbidity. ${ }^{4,5}$ Despite this, perioperative bleeding and pancreatic leakage still remain a challenge for the surgeons. General morbidity rate and perioperative hemorrhage is generally lower for laparoscopic procedures ${ }^{6}$, but there is no 
conclusive evidence that minimally invasive surgery leads to reduced POPF rate after distal pancreas resections. Various centers have published different rates of POPF varying from $0 \%$ to $32 \%$ as defined by the International study group on pancreatic fistulas (ISGPF). ${ }^{7}$ In our institution, the overall fistula rate after laparoscopic resections of the pancreas has been $10 \%{ }^{2}$

The continuous search for the new and more effective remedies and techniques to prevent POPF remains is important. In January 2005, we introduced the surgical patch TachoSil ${ }^{\circledR}$ (Nycomed, Pharmaceutical Co. Ltd, Denmark) to cover the resection margin of the pancreas after laparoscopic resections. It was announced as a fast and reliable remedy for haemostasis and sealing of soft tissues. These argued characteristics corresponded to our needs in order to prevent postoperative complications. This study evaluated TachoSil as a prevention remedy for postoperative pancreatic fistula (POPFs) in pancreatic surgery.

\section{Patients and Methods}

\section{Patients}

A total of 230 patients underwent laparoscopic pancreas resections in our institution from March 1997 to December 2010. After exclusion of local tumor resections $(n=36)$, procedures with additional resections of adjacent organs $(n=29)$, procedures where other types of protection of surgical margin were used $(n=14)$, converted procedures or accomplished as hand assisted $(n=5)$, and explorative and other types of procedures $(n=25)$ a total of 121 patients undergoing distal pancreatic resection (DPR) with or without splenectomy, were left for analysis. All procedures were performed by the same group of surgeons. From January 2005 majority of the procedures have been completed with covering of surgical margin and part of pancreatic remnant by TachoSil patch for to prevent postoperative pancreatic fistulas and potential postoperative bleeding. To that time not all effects of this remedy were clear and good documented, especially about its effectiveness in pancreatic surgery.

Indications to surgical procedures were endocrine tumors, cystic lesions, adenocarcinomas, and others as described in our previous publication.

The patients were retrospectively divided in two groups according to the final management of the surgical margin. In the first group (group 1, consisting of 48 patients (32 women and 16 men) with a median age of $62(30-81)$ years and median ASA score of $2(1-3)$ ), the pancreas was divided by a linear stapler and left without additional covering. In the second group (group 2, consisting of 73 patients (49 women and 24 men) with a median age of 60
(16-82) years and median ASA score of $2(1-3))$, the staple line of the resection margin was covered with a TachoSil ${ }^{\circledR}$ patch. As our method for pancreas division has been described in detail earlier, ${ }^{2,8}$ this study focused only on the final part of the procedure.

Data were analyzed retrospectively. Patient's characteristics are presented in Table 1.

\section{Outcome Parameters}

According to the ISGPF definition, pancreatic fistula was defined as a drainage fluid beyond the third postoperative day with at least threefold elevation of normal serum amylase. The grading system (grades A, B, and C) of severity of pancreatic fistula was applied (Table 2). ${ }^{9}$

Postoperative complications were registered in accordance with a last revision of the accordion classification, from mild complications (grade 1) to death of the patient - (grade 6) as described in Table $3 .^{10}$

\section{Statistical Analysis}

Statistical analysis was conducted using SPSS 16, 0. Data were presented as median (range). For comparison of frequencies, the Chi-square test was performed. For comparison of the continuous variables, Mann-Whitney $U$ test was used.

\section{Results}

Out of 230 patients, 121 were included in this study of which 91 were DPR with splenectomy and 30 were DPR performed as spleen-preserving procedures. Details regarding the indications for surgery are summarized in Table 4 . All procedures were completed laparoscopically. Data regarding the surgical details are described in Table 5:

In group 1, 38 DPR with splenectomy and ten spleenpreserving resections were performed without using TachoSil. The median operative time for these procedures was 202 (29-350) minutes and the median intraoperative bleeding was $50(0-1,500) \mathrm{ml}$. There were three grade 1 , two grade 2, four grade 3, and two grade 4 events. Four

Table 1 Patient characteristics

\begin{tabular}{lll}
\hline & Group 1 & Group 2 \\
\hline Patients & 48 & 73 \\
Gender & 32 women & 49 women \\
& 16 men & 24 men \\
Median age (years) & $62(30-81)$ & $60(16-82)$ \\
Median ASA score & $2(1-3)$ & $2(1-3)$ \\
\hline
\end{tabular}


Table 2 Main parameters for POPF grading

US ultrasonography, $C T$ computed tomographic scan, $P O P F$ postoperative pancreatic fistula

${ }^{\text {a }}$ Partial (peripheral) or total parenteral nutrition, antibiotics, enteral nutrition, somatostatin analog, and/or minimal invasive drainage

${ }^{b}$ With or without a drain in situ

\begin{tabular}{llll}
\hline Grade & A & B & C \\
\hline Clinical conditions $^{\text {Specific treatment }}{ }^{\mathrm{a}}$ & Well & Often well & Ill appearing/bad \\
US/CT (if obtained) & No & Yes/no & Yes \\
Persistent drainage (after 3 weeks) ${ }^{\text {b }}$ & Negative & Negative/positive & Positive \\
Reoperation & No & Usually yes & Yes \\
Death related to POPF & No & No & Yes \\
Signs of infections & No & No & Possibly yes \\
Sepsis & No & Yes & Yes \\
Readmission & No & No & Yes \\
\hline
\end{tabular}

patients developed pancreatic fistula of which all were grade $\mathrm{B}$. The overall morbidity in the group was 30\%. The median duration of postoperative hospital stay for group 1 was 5 (2-16) days.

In group 2, we included only those procedures where the pancreatic remnant was covered with TachoSil ${ }^{\circledR}$. In this group, 53 procedures were DPR with splenectomy and 20 spleen-preserving DPR. The median operative time was 158 (88-608) $\mathrm{min}$, and the median intraoperative bleeding was $50(5-3,000) \mathrm{ml}$. The postoperative morbidity included four grade 1 event, three grade 2, one grade 3 event, and three grade 4 events. Postoperative pancreatic leakage was registered in ten patients of which one grade $\mathrm{A}$, six grade $\mathrm{B}$, and three grade $\mathrm{C}$ fistulas. The overall morbidity rate in group 2 was $30 \%$, and the median duration of postoperative hospital stay was 5.5 (2-35) days.

Table 3 Revised accordion classification

Grade Revised accordion classification

Mild

1 Requires only minor invasive procedures that can be done at the bedside, such as insertion of intravenous lines, urinary catheters, and nasogastric tubes and drainage of wound infections. Physiotherapy and anti-emetics, antipyretics, analgesics, diuretics, electrolytes, and physiotherapy are permitted

Moderate

2 Requires pharmacologic treatment with drugs other than such allowed for minor complications, e.g., antibiotics. Blood transfusions and total parenteral nutrition are also included

Severe

3 No general anesthesia: requires management by an endoscopic, interventional procedure or reoperation without general anesthesia

4 General anesthesia or single-organ failure

5 General anesthesia and single-organ failure or multisystem organ failure ( $>2$ organ systems)

Death

$6 \quad$ Postoperative death
No postoperative mortality was recorded in any of the groups. Detailed description over all postoperative complications is shown in Table 6. We did not find statistical difference in postoperative data between these two groups.

\section{Discussion}

Laparoscopic DPR have steadily gained acceptance as a method for surgical removal of both benign and malignant lesions in the tail and body of the pancreas.

The technique not only shows better cosmetic results but is also associated with reduced bleeding and overall morbidity rate compared with traditional open surgery. ${ }^{11}$ It is unclear if the method influences the rate of postoperative pancreatic leakage since no randomized studies has been conducted while comparing the techniques. There are, however, studies in which a trend has been reported about nonsignificant reduced rate of POPF after minimally invasive procedures. ${ }^{6}$

Pancreatic leakage is one of the most commonly encountered severe complications following pancreatic resections and leak rates up to $46 \%$ has been described. ${ }^{12}$ Several different techniques have been attempted in order to prevent fistulas and some authors mean that management of

Table 4 Summary of details regarding the indications for surgery

\begin{tabular}{lll}
\hline Indication to surgery & Group 1 & Group 2 \\
\hline Cystic lesions & 17 & 34 \\
PNET & & \\
Malign lesions & 6 & 4 \\
Benign lesions & 15 & 14 \\
Exocrine adenocarcinoma & 5 & 9 \\
Metastatic lesions & 2 & 0 \\
Pancreatitis & 1 & 9 \\
Abdominal trauma & 0 & 1 \\
Vascular formation & 2 & 2 \\
Total & 48 & 73 \\
\hline
\end{tabular}


Table 5 Data regarding surgical details

\begin{tabular}{llll}
\hline Surgical outcomes & Group $1^{\mathrm{a}}$ & Group $2^{\mathrm{b}}$ & $p$ value \\
\hline DPR with splenectomy & 38 & 53 & \\
Spleen-preserving resections & 10 & 20 & $158(88-480)$ \\
Operative time (min) & $202(29-350)$ & $50(0-3,000)$ & 0.810 \\
Bleeding (ml) & $50(0-1,500)$ & $5.5(2-35)$ & 0.970 \\
Duration of postoperative hospital stay & $5(2-16)$ & 0.203 \\
\hline
\end{tabular}

PNET pancreatic neuroendocrine tumor

${ }^{\text {a }}$ Pancreatic stump was not covered

${ }^{\mathrm{b}}$ Resectional pancreatic stump was covered with TachoSil patch

the resectional margin of pancreatic stump is very important. To develop a standardized technique which can demonstrate a significant decrease in overall morbidity including fistula formation is important.

Better results and safety of the patient is a major concern of any surgical procedures and laparoscopic pancreas resection is no exception. One contribution for the decreased overall morbidity in pancreatic surgery during the last years is the introduction of new staplers, electrosurgical instruments, surgical methods, and other technical and pharmaceutical remedies. TachoSil ${ }^{\circledR}$ is a fixed combination of a patch sponge coated with a dry layer of the human coagulation factors fibrinogen and thrombin. TachoSil ${ }^{\circledR}$ is indicated for supportive treatment in surgery, for improvement of haemostasis, to promote tissue sealing and for suture support in vascular surgery where standard techniques are insufficient.

The haemostatic effect of Tachosil patch in surgical procedures is well documented in the literature ${ }^{13}$ in a wide variety of organs. ${ }^{14}$

Since the TachoSil ${ }^{\circledR}$ patch was also reported to be of value in terms of sealing surgical resection surfaces; we postulated it to be of value also in pancreas resections in which fistula formation continued to constitute a problem. Covering of the stapling line on the cut surface of the pancreas therefore became a routine part of the procedure since 2005 .

It was described as predicting factors for development of pancreatic fistulas ${ }^{15}$, and we tried to look if TachoSil ${ }^{\circledR}$

Table 6 Detailed description over all postoperative complications

\begin{tabular}{|c|c|c|c|}
\hline Postoperative complications & Group $1^{\mathrm{a}}$ & Group $2^{\mathrm{b}}$ & $p$ value \\
\hline Fistula formation & $4(8 \%)$ & $10(14 \%)$ & 0,487 \\
\hline Grade A & 0 & 1 & \\
\hline Grade B & 4 & 6 & \\
\hline Grade C & 0 & 3 & \\
\hline Other morbidity & $11(23 \%)$ & $11(15 \%)$ & \\
\hline \multicolumn{4}{|l|}{ Severity grade } \\
\hline \multicolumn{4}{|l|}{ Mild } \\
\hline 1 & $\begin{array}{l}4-2 \text { small hematomas around the resection } \\
\text { area, urine retention, and wound infection }\end{array}$ & $\begin{array}{l}3 \text { - urine retention, pleural liquid collection, } \\
\text { and wound infection }\end{array}$ & \\
\hline \multicolumn{4}{|l|}{ Moderate } \\
\hline 2 & 3 - postoperative abscess and 2 fibers & $\begin{array}{l}2 \text { - postoperative bleeding and subcapsular } \\
\text { splenic hematoma }\end{array}$ & \\
\hline \multicolumn{4}{|l|}{ Severe } \\
\hline 3 & 1 -intraabdominal abscess & $\begin{array}{l}\text { 4-Abscess in operation area, subphrenic } \\
\text { hematoma, and } 2 \text { wound fractures }\end{array}$ & \\
\hline 4 & 3 - postoperative bleeding & 2 -bleeding and myocardial infarction & \\
\hline 5 & 0 & 0 & \\
\hline \multicolumn{4}{|l|}{ Death } \\
\hline 6 & 0 & 0 & \\
\hline Overall morbidity & $15(30 \%)$ & $21(30 \%)$ & \\
\hline
\end{tabular}

${ }^{\text {a }}$ Pancreatic stump was not covered

${ }^{\mathrm{b}}$ Resectional pancreatic stump was covered with TachoSil patch 
patch could be beneficial in special cases. In the present series, we found that in the first group (without application of TachoSil) fistulas were registered only in soft glands whereas in the second (where TachoSil was applied on the resectional line) $30 \%$ (three out of ten) of all fistulas developed in the hard glands. To make any conclusions based on these results is difficult. We did not experience serious blood loss $(\leq 1,000 \mathrm{ml})$ in any of these cases.

When we designed this retrospective study we were aware about its limitations and have tried to diminish their possibility. To avoid selection bias only distal resections with or without splenectomy independent of other factors (age, pathology, etc.) were included to the study. Chances that some of the patients fall out of control were equal for both groups. However, due to general low rate of fistulas in our material, one should be aware about possibility of statistical type 2 error.

In this study, however we did not observe significant differences in any of the studied parameters between patients in whom stapling line was covered by TachoSil patch after the resection and those without it. Somewhat surprisingly, grade $\mathrm{C}$ fistulas were only observed in patients in group 2, in which TachoSil ${ }^{\circledR}$ was used. The reason for this is unclear. One possible explanation could be that reducing of the natural outflow from the pancreatic remnant can lead to accumulation of ferments and thereby impair the normal process of postoperative healing. To make any conclusion about this, randomized studies are needed.

The haemostatic effect of TachoSil ${ }^{\circledR}$ in various procedures makes the product of great value in complex laparoscopic procedures.

Present data do not support the use of the TachoSil ${ }^{\circledR}$ patch for the prevention of fistulas following distal pancreatic resections.

Conflicts of Interest The authors declare that they have no conflict of interest.

Open Access This article is distributed under the terms of the Creative Commons Attribution Noncommercial License which permits any noncommercial use, distribution, and reproduction in any medium, provided the original author(s) and source are credited.

\section{References}

1. Cuschieri, S. A., and Jakimowicz, J. J. Laparoscopic pancreatic resections. Semin. Laparosc. Surg. 5:168-179, 1998.

2. Rosok, B. I., Marangos, I. P., Kazaryan, A. M., Rosseland, A. R., Buanes, T., Mathisen, O., and Edwin, B. Single-centre experience of laparoscopic pancreatic surgery 191. Br. J. Surg. 97:902-909, 2010.

3. Fernandez-Cruz, L., Herrera, M., Saenz, A., Pantoja, J. P., Astudillo, E., and Sierra, M. Laparoscopic pancreatic surgery in patients with neuroendocrine tumours: indications and limits. Best Practice and Research Clinical Endocrinology and Metabolism 15:161-175, 2001.

4. Bassi, C., Butturini, G., Molinari, E., Mascetta, G., Salvia, R., Falconi, M., Gumbs, A., and Pederzoli, P. Pancreatic fistula rate after pancreatic resection. The importance of definitions. Dig. Surg. 21:54-59, 2004.

5. DeOliveira, M. L., Winter, J. M., Schafer, M., Cunningham, S. C., Cameron, J. L., Yeo, C. J., and Clavien, P. A. Assessment of complications after pancreatic surgery: a novel grading system applied to 633 patients undergoing pancreaticoduodenectomy 6 . Ann. Surg. 244:931-937, 2006.

6. Nigri, G. R., Rosman, A. S., Petrucciani, N., Fancellu, A., Pisano, M., Zorcolo, L., Ramacciato, G., and Melis, M. Metaanalysis of trials comparing minimally invasive and open distal pancreatectomies 1. Surg. Endosc. 25(5):1642-1651, 2010

7. Kooby, D. A., Gillespie, T., Bentrem, D., Nakeeb, A., Schmidt, M. C., Merchant, N. B., Parikh, A. A., Martin, R. C., Scoggins, C. R., Ahmad, S., Kim, H. J., Park, J., Johnston, F., Strouch, M. J., Menze, A., Rymer, J., McClaine, R., Strasberg, S. M., Talamonti, M. S., Staley, C. A., McMasters, K. M., Lowy, A. M., Byrd-Sellers, J., Wood, W. C., and Hawkins, W. G. Left-sided pancreatectomy: a multicenter comparison of laparoscopic and open approaches 8. Annals of Surgery 248:438-446, 2008.

8. Edwin, B., Mala, T., Mathisen, O., Gladhaug, I., Buanes, T., Lunde, O. C., Soreide, O., Bergan, A., and Fosse, E. Laparoscopic resection of the pancreas: a feasibility study of the short-term outcome 14. Surgical Endoscopy 18:407-411, 2004.

9. Bassi, C., Dervenis, C., Butturini, G., Fingerhut, A., Yeo, C., Izbicki, J., Neoptolemos, J., Sarr, M., Traverso, W., and Buchler, M. Postoperative pancreatic fistula: an international study group (ISGPF) definition. Surgery 138:8-13, 2005.

10. Porembka, M. R., Hall, B. L., Hirbe, M., and Strasberg, S. M. Quantitative weighting of postoperative complications based on the accordion severity grading system: demonstration of potential impact using the american college of surgeons national surgical quality improvement program 2. J. Am. Coll. Surg. 210:286-298, 2010.

11. Weber, S. M., Cho, C. S., Merchant, N., Pinchot, S., Rettammel, R., Nakeeb, A., Bentrem, D., Parikh, A., Mazo, A. E., Martin, R. C., III, Scoggins, C. R., Ahmad, S. A., Kim, H. J., Hamilton, N., Hawkins, W., Max, S. C., and Kooby, D. A. Laparoscopic left pancreatectomy: complication risk score correlates with morbidity and risk for pancreatic fistula. Ann. Surg. Oncol. 16:2825-2833, 2009.

12. Moskovic, D. J., Hodges, S. E., Wu, M. F., Brunicardi, F. C., Hilsenbeck, S. G., and Fisher, W. E. Drain data to predict clinically relevant pancreatic fistula. HPB (Oxford) 12:472481, 2010.

13. Siemer, S., Lahme, S., Altziebler, S., Machtens, S., Strohmaier, W., Wechsel, H. W., Goebell, P., Schmeller, N., Oberneder, R., Stolzenburg, J. U., Becker, H., Luftenegger, W., Tetens, V., and Van, P. H. Efficacy and safety of TachoSil as haemostatic treatment versus standard suturing in kidney tumour resection: a randomised prospective study 1. Eur. Urol. 52:1156-1163, 2007.

14. Kazaryan, A. M., Pavlik, M., I, Rosseland, A. R., Rosok, B. I., Mala, T., Villanger, O., Mathisen, O., Giercksky, K. E., and Edwin, B. Laparoscopic liver resection for malignant and benign lesions: ten-year Norwegian single-center experience 4. Arch. Surg. 145:34-40, 2010.

15. Pratt, W. B., Callery, M. P., and Vollmer, C. M., Jr. Risk prediction for development of pancreatic fistula using the ISGPF classification scheme 8. World J. Surg. 32:419-428, 2008. 